\title{
Laparoscopic Appendectomy for Giant Appendiceal Mucocele in an Elderly Patient: A Case Report
}

\author{
Yusuf Tanrikulu $^{\mathrm{a}, \mathrm{c}}$, Ceren Sen Tanrikulu ${ }^{\mathrm{b}}$, Volkan Temi ${ }^{\mathrm{a}}$, Boran Yalcin ${ }^{\mathrm{a}}$
}

\begin{abstract}
Appendiceal mucoceles are cystic lesions of the appendix resulting from mucus accumulation of lumen, and it is uncommon. Definitive treatment of appendiceal mucoceles is surgical. Nowadays, laparoscopic resection of appendiceal mucoceles has been well described, but the efficacy and safety are still polemic because intra-operative complications related to surgery directly affect prognosis. We presented a laparoscopic resection of a giant appendiceal mucocele in a 60-year-old female patient.
\end{abstract}

Keywords: Appendix; Laparoscopy; Mucinous cystadenoma; Mucocele

\section{Introduction}

Mucocele of appendix is an obstructive dilatation of the appendiceal lumen by accumulation of mucus. It is a rare pathology of the appendix and the incidence is $0.2-0.7 \%$ in appendectomy cases [1]. There are four subgroups of appendiceal mucoceles according to their histopathological structure: retention cyst, mucosal hyperplasia, mucinous cystadenoma and mucinous cystadenocarcinoma [2]. The laparoscopic appendectomy is broadly used for the acute appendicitis while it is still controversial for the appendiceal mucocele [3]. In this study, we presented a case of laparoscopic appendectomy for a giant appendiceal mucocele in an elderly patient.

\footnotetext{
Manuscript accepted for publication June 9, 2014

${ }^{a}$ Department of General Surgery, Zonguldak Ataturk State Hospital, Zonguldak, Turkey

${ }^{b}$ Department of Emergency Medicine, Faculty of Medicine, Bulent Ecevit University, Zonguldak, Turkey

${ }^{\mathrm{c}}$ Corresponding Author: Yusuf Tanrikulu, Zonguldak Ataturk Devlet Hastanesi, Genel Cerrahi Klinigi, 67100 Zonguldak, Turkey.

Email: drtanrikulu@hotmail.com
}

doi: http://dx.doi.org/10.14740/jmc1829e

\section{Case Report}

A 60-year-old female patient was admitted to our clinic with abdominal pain for 6 months. There was not additional complaint of patient (e.g., musculosceletal, genitourinary). On physical examination, vital signs were stable. There was tenderness in the right lower quadrant. There was not rebound and tenderness. Rectal examination was normal. The laboratory analysis was not noticeable. Ultrasonography (USG) showed a cystic lesion is $7 \times 4 \mathrm{~cm}$ in size, hyperechoic, avascular, complex in the right adnexal area. Magnetic resonance imaging (MRI) revealed a cystic mass with thin septal in same dimensions, in anterior of the psoas muscle in the lower right quadrant (Fig. 1). MR image was primarily thought mesenteric cysts. Diagnostic laparoscopy was decided to detect mass. Laparoscope was inserted through a supraumbilical incision. Laparoscopic examination detected an inmobile mass in right paracolic area. The mass is hard, fixed to the retroperitoneal region, arising from the appendix, approximately $8 \times 5 \mathrm{~cm}$ in size (Fig. 2, 3). There was not ascites, finding of primary and/or metastatic malignancy, and genitourinary pathology. Trocars were placed on the suprapubic area and left lower quadrant. The mass was released from the lateral wall and mesoappendix by the ultrasurgical device (ENSEAL ${ }^{\circledR}$ G2 Curved and Straight Tissue Sealers). Radix of appendix was normal. The mass was excised together with appendix by the endo stapling device (Endo GIATM Universal Stapling System). The specimen was extracted through the extended suprapubic incision using endobag. Histopathological examination showed a diagnosis of a mucinous cysadenoma, $9 \times 4 \mathrm{~cm}$ in size (Fig. 4). The patient with normal postoperative course was discharged on the second day. There was no abnormal condition in clinical follow-up of patient.

\section{Discussion}

In this study, diagnosis and treatment of appendiceal mucocele have been discussed in the literature. The mucoceles of the appendix, first identified in 1842 by Rokitansky [4], 

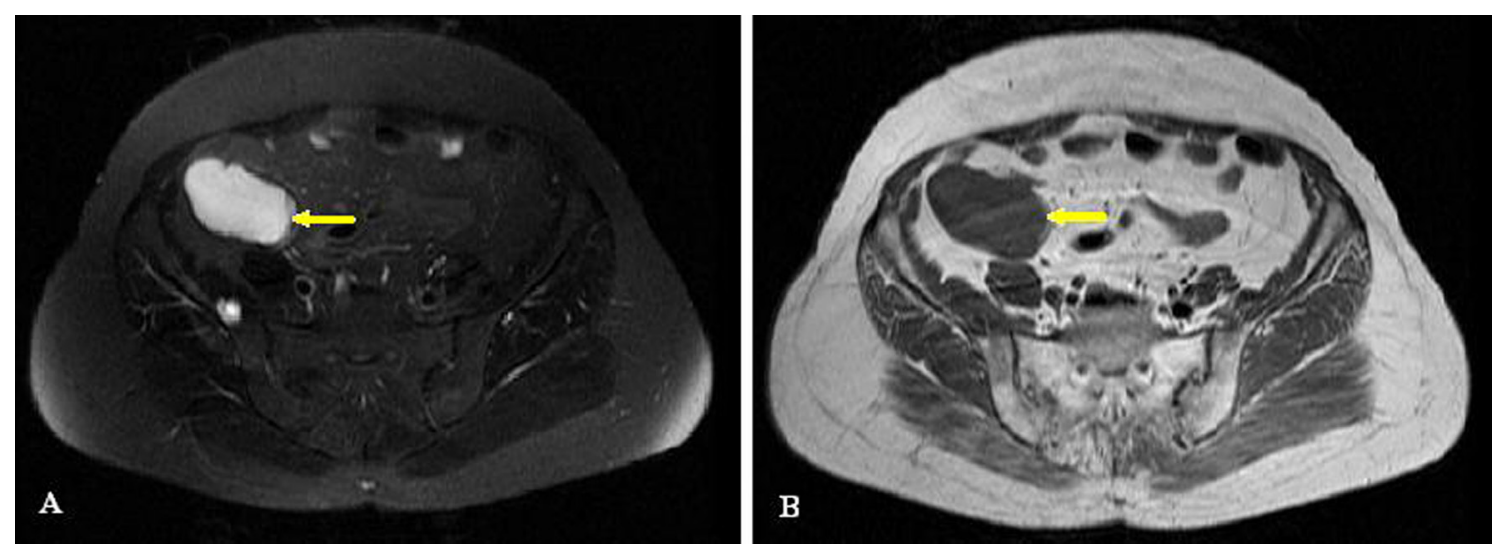

Figure 1. MRI of mass: (A) T2 sequence; (B) T1 sequence.

are the cystic lesions characterized by appendiceal lumen of the appendix with full of mucoid material, obstruction and dilatation, mucosal structure distortion and mucus hypersecretion. The frequency of appendectomy patients varies between $0.7 \%$ and $0.2 \%$, especially in the women, above 50 years old, which is more frequently seen [5].

According to the modern classification of World Health Organization, appendix mucoceles are divided into four subgroups by the presence or absence of mucus, hypersecretion and dysplastic features: retention cyst, mucosal hyperplasia, mucinous cystadenoma and mucinous cystadenocarcinoma $[2,6]$.

Clinical manifestations are nonspecific and 25\% of patients are asymptomatic. Common clinical signs include right lower quadrant pain, change in bowel habits and rectal bleeding rarely. Sometimes symptoms may resemble acute appendicitis. Pre-operative diagnosis of appendiceal mucocele is very important for the treatment and follow-up process of the disease. Abdominal imaging modalities such as USG, computed tomography and MRI can be used for its diagnosis. USG is used to rule out acute appendicitis. Crosssectional imaging is important in assessing the cyst size,

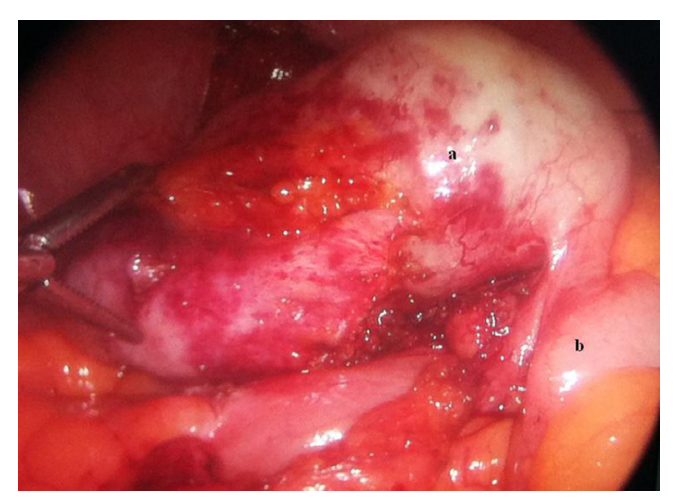

Figure 2. Intra-operative laparoscopic picture of cystic mass of appendix: (a) appendix mucocele; (b) cecum. structure, location and relationship of the surrounding structures. Colonoscopy is not often used for the diagnosis [1].

The treatment of appendiceal mucocele is always surgical. The surgical procedure is very important, so perforation of mucoceles may cause pseudomyxoma peritonei by mucoid material to diffuse into the abdomen. Conventional or laparoscopic surgical procedures can be used. Some authors prefer laparoscopic surgical procedures due to paced technological advancements, better viewing angles and the benefits of minimally-invasive procedures (e.g., advantages such as early mobilization, day treatment and reduced pain). But some authors are avoiding the laparoscopic surgical procedures because they can increase the rupture risk of the mucocele as well as the pseudomyxoma peritonei [7]. In the literature, publications are available showing that the laparoscopic treatment even for large-scale mucocele is successful and advantageous $[8,9]$.

Surgical specimen width varies with the tumor size, histological structure and lymph node involvement [10]. Simple appendectomy procedure is adequate for the simple cysts, mucus hyperplasia and mucinous cystadenomas, but right hemicolectomy procedure should be done in the cystadenocarcinomas and lymph node involvement [3].

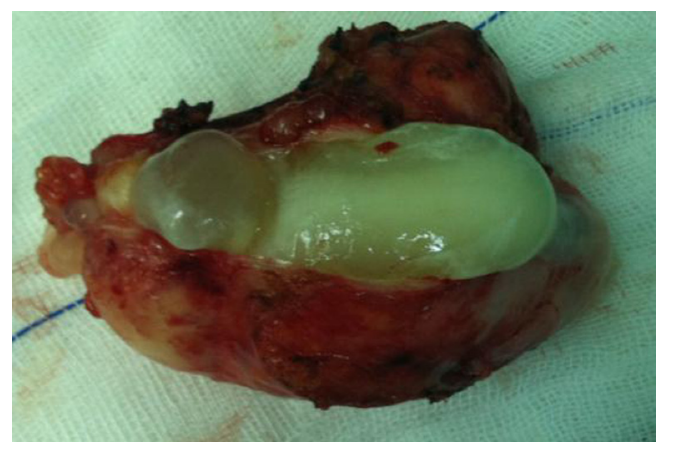

Figure 3. Macroscopic picture of appendix mucocele after resection. 

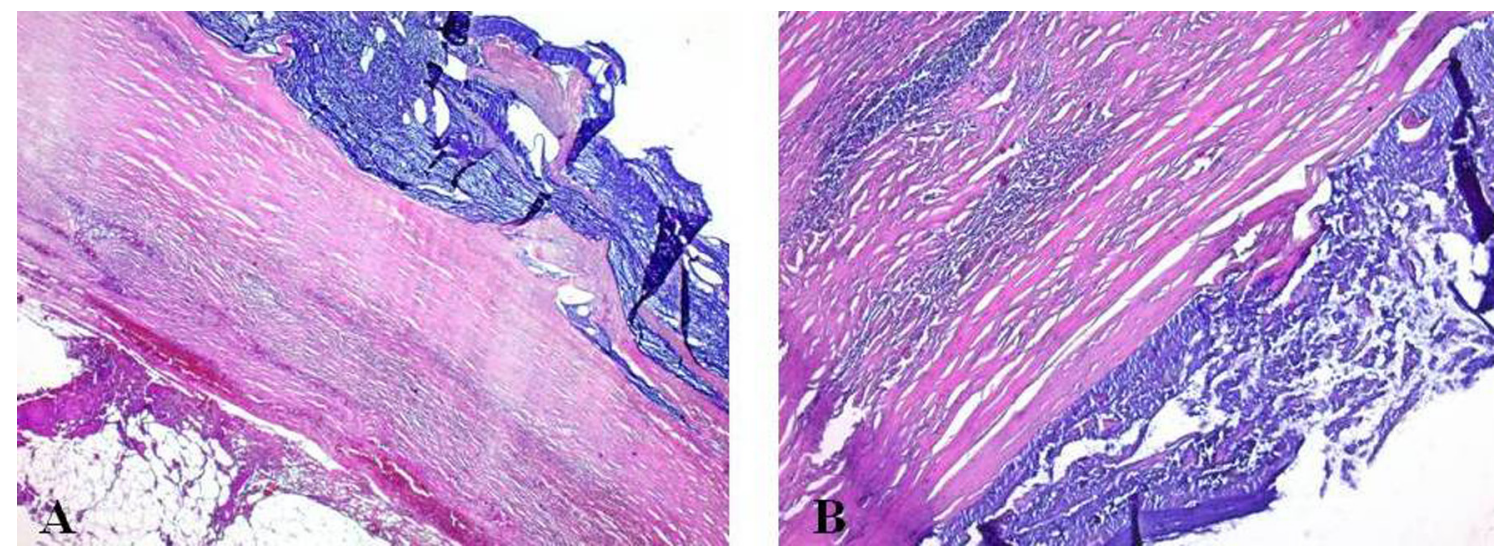

Figure 4. Histopathological imaging of appendix mucocele (extensive mucus in appendiceal lumen, atrophy of the mucosa and wall thinning of appendiceal, and chronic inflammatory cell infiltration, H\&E): $(A) \times 50$; $(B) \times 100$.

Especially, prognosis in the benign appendix mucocele is so good that 5 -year survival rate is close to $100 \%$, but it is $45 \%$ in cases which the tumor perforated. Therefore, it does not require long-term follow-up in non-perforated patients, and perforated patients need long-term closely spaced follow-up [11].

As a result, the possibility of appendiceal tumors should be considered in patients in advanced age with chronic or acute abdominal pain, and detailed review should be made for the pre-operative diagnosis. The definitive treatment of the appendix mucocele is surgery, and the laparoscopic procedure can be done successfully depending on the tumor histological type, size and the surgeon's experience, for the clinical diagnosis of the disease, and in cases where the mucocele perforated, the close follow-up is needed.

\section{Conflict of Interest}

There is no ethical problem and/or conflict of interest between the top author and co-authors.

\section{References}

1. Demetrashvili Z, Chkhaidze M, Khutsishvili K, Topchishvili G, Javakhishvili T, Pipia I, Qerqadze V. Mucocele of the appendix: case report and review of literature. Int Surg. 2012;97(3):266-269.

2. Kim-Fuchs C, Kuruvilla YC, Angst E, Weimann R, Gloor B, Candinas D. Appendiceal mucocele in an el- derly patient: how much surgery? Case Rep Gastroenterol. 2011;5(3):516-522.

3. Ju YT, Park ST, Ha WS, Hong SC, Lee YJ, Jung EJ, Jung CY, et al. Laparoscopic resection of a appendiceal mucocele. J Korean Surg Soc. 2011;80(Suppl 1):21-25.

4. Rokitansky KF. Beritrage zur Erkrankungen der Wurmfortsazentzundung. Wien Med Presse. 1866;26(1):428435.

5. Caliskan K, Yildirim S, Bal N, Nursal TZ, Akdur AC, Moray G. Mucinous cystadenoma of the appendix: a rare cause of acute abdomen. Ulus Travma Acil Cerrahi Derg. 2008;14(4):303-307.

6. Higa E, Rosai J, Pizzimbono CA, Wise L. Mucosal hyperplasia, mucinous cystadenoma, and mucinous cystadenocarcinoma of the appendix. A re-evaluation of appendiceal "mucocele". Cancer. 1973;32(6):1525-1541.

7. Goyal A, Goyal S, Bagree R, Sharma S, Jindel DK. Giant mucocele of appendix as pelvic mass: A rare presentation. Indian J Surg. 2010;72(Suppl 1):347-348.

8. Lau H, Yuen WK, Loong F, Lee F. Laparoscopic resection of an appendiceal mucocele. Surg Laparosc Endosc Percutan Tech. 2002;12(5):367-370.

9. Chiu CC, Wei PL, Huang MT, Wang W, Chen TC, Lee WJ. Laparoscopic resection of appendiceal mucinous cystadenoma. J Laparoendosc Adv Surg Tech A. 2005;15(3):325-328.

10. De Abreu Filho JG, De Lira EF. Mucocele of the Appendix - appendectomy or colectomy. Rev bras Coloproct 2011;31(3):276-284.

11. Rampone B, Roviello F, Marrelli D, Pinto E. Giant appendiceal mucocele: report of a case and brief review. World J Gastroenterol. 2005;11(30):4761-4763. 